\title{
Facing Aggressiveness in Face-to-Face Arguing
}

\author{
Iryna Khomenko
}

Doctor of Philosophical Sciences, Professor, Taras Shevchenko National University of Kyiv (Kyiv, Ukraine)

E-mail: khomenkoi.ukr1@gmail.com

https://orcid.org/0000-0003-3522-2271

\section{Kateryna Bura}

Master degree student, Taras Shevchenko National University of Kyiv (Kyiv, Ukraine)

E-mail: katerynabura@gmail.com

https://orcid.org/0000-0003-4147-9751

The Ukrainian identity issue is crucial for the future development of Ukraine as an independent country. In this regard, any research intended to address this issue is highly important. Among them is the project presented in this paper. In our opinion, its results may have an impact on the understanding of key traits of the Ukrainian identity. Its purpose is in general to examine Ukrainian predispositions and understandings regarding interpersonal communication and, in particular, aggressiveness in face-to-face arguing. We have conducted empirical research to seek the views of young Ukrainians on aggressiveness in verbal and non-verbal argumentation. Here we have presented key findings of our research, discoveries and generalizations that have attracted our attention.

Keywords: aggressiveness, interpersonal arguing, argumentation, empiricalization, Ukrainian identity

Received: February 26, 2019; accepted: March 29, 2019

Ukrainian Policymaker, Volume 4, 2019: 13-20.

https://doi.org/10.29202/up/4/2

\section{Introduction}

Nowadays study of argumentation involves theoretical as well as empirical components. However, in the $20^{\text {th }}$ century investigations in the field of argumentation were mainly aimed at theoretical proposals and their philosophical support. Argumentation scholars mostly focused on the development of fundamental principles, ideas, and theoretical models.

Only more recently empiricalization has become a new trend among researchers [Eemeren, 2015; 2017]. For example, Frans Eemere considers empiricalization as one of the main

(C) Khomenko, Iryna, 2019

(C) Bura, Kateryna, 2019 
prospects of current argumentation study [see: Eemeren, 2015; 2017]. In his opinion, "three major developments in the treatment of argumentation have begun to materialize that open new avenues for research. Although they differ in shape, these developments can be observed across a broad spectrum of theoretical approaches. The three developments I have in mind can be designated as empiricalization, contextualization, and formalization of the treatment of argumentation" [Eemeren, 2015: 5].

Let us deal with what is empiricalization of the treatment of argumentation. It should be noted that a key feature of empirical research is to use empirical evidence as a way of gaining results. The term empirical evidence refers to the systematic collection and analysis of data related to the field of argumentation. Scholars may involve a variety of instruments [Khomenko, 2018]. For example, in empirical research of various historical texts Maurice Finocchiaro used the method of alternative conclusion, active evaluation, ad hominem argument, the method of counterexample, the principle of charity, and explanation of the error in reasoning. In his mind, the first three methods are the most relevant for his historical-textual approach of argumentation [Finocchiaro, 1980; 1994; 2005; 2010]. Besides, Maurice Finocchiaro elaborated the method of meta-argumentation based on the principle of interpretation and evaluation [Finocchiaro, $2013]$.

Also, scholars in order to collect data often use a survey as an instrument of such research [Hample, 2003; 2005; 2018]. It bases on the questionnaire, which is a research instrument consisting of a series of questions for the purpose of gathering information from respondents. Data can be collected relatively quickly, using a standard set of questions. A survey is useful for a large number of participants.

Empirical evidence can be analyzed quantitatively as well as qualitatively. Many argumentation scholars combine both forms of analysis to better answer questions which cannot be studied in artificial laboratory settings.

These days empirical methodology is very popular in the field of cross-cultural research, particularly it can be reasonably applied to the goal of understanding how people with different cultural traditions relate to face-to-face arguing. Among the appropriate approaches in this field is the one selected here. Its orientation is to examine predispositions and understandings regarding interpersonal arguing. Its main objective is to collect and analyze the data summarizing fundamental orientations to arguing among respondents. All of the instruments of this research originated in the US. It should be stressed that besides elucidating the argumentation predispositions in a certain country this approach advances the general project of comparing argumentation in various countries across the globe [Hample, 2018]. To date, the United States, Chile, China, France, India, Malaysia, Mexico, Netherlands, Portugal, South Korea, Turkey, and United Arab Emirates have already participated in this global project [see, Hample \& Anagondahalli, 2015; Hample \& Rapanta, 2015; Lewiński et al., 2018].

In 2018, Ukraine jointed this international project. It was the first comprehensive attempt to understand and assess the sentiments of Ukrainians towards face-to-face arguing. The main objective of the cross-cultural project was to collect and analyse data summarizing fundamental orientations to arguing among Ukrainians. After its completion, we believed it essential to continue working towards improving our knowledge in this research field. At the end of 2018 such frame as aggressiveness was selected as a subject matter of the new project.

In view of the above, we identify the goal of this paper is to present received under the investigation key findings, discoveries, and generalization concerning Ukrainian predispositions and understandings regarding aggressiveness in face-to-face arguing. 


\section{Research objectives}

In 2018, a nationwide survey was conducted in Ukraine within the international crosscultural project. One of the main research questions was the following: how does Ukrainian and US respondents compare in their average responses concerning arguing motivations, understandings, and reactions?

After data collection and its analysis, we concluded that Ukrainians do not like to be involved in face-to-face arguing because it is considered to be a hostile incursion into their personal world or conflict and aggressive activity that tends to destroy their life and aggravate the interpersonal relations. If they are obliged to participate in such form of communication they mainly will not behave aggressively, offend people, incite hatred and provoke violence. The majority of Ukrainians are predominantly tolerant, peaceful, friendly, and open to others. In most cases, they try to be polite, to express respect for others and to argue constructively.

At the same time, understanding of face-to-face arguing solely as a destructive conflict tending to damage relationships may be considered as the reason why Ukrainians are less inclined to understand arguments as professionals do.

At the beginning of 2019, a new research project concerning Ukrainian youth attitudes to face-to-face arguing was opened. Its subject matter was such frame of arguing as aggressiveness. Some ideas of argumentation scholars a sufficiently strong basis of this project [see, Hample, 2003, 2005, 2018; Hample \& Irions, 2015; Hample \& Cionea, 2010; Hample et al., 2010; Hample \& Dallinger, 1995; Infante \& Wigley, 2009; Infante \& Rancer, 1982]. Taking into account that verbal aggressiveness has been already studied within the previous project we primarily focused on non-verbal argumentation.

Thus, the main objective of this project was to explore the general attitudes of Ukrainian youth to aggressiveness in face-to-face arguing.

In this regard, we chose to pose such research questions.

RQ1. What are Ukrainian youth attitudes towards aggressiveness within interpersonal communication?

RQ2. Do the results of the present project confirm the findings on aggressiveness received within the survey-2018?

RQ3. What are the reasons for increasing the level of aggressiveness in face-to-face arguing?

\section{Sample}

The empirical part of the project included the survey and experiment conducted in March 2019. 14 respondents were interviewed. Among them were 11 women and 3 men. All respondents (100\%) were enrolled in Taras Shevchenko National University of Kyiv (Ukraine) at the time they completed the survey and participated in the experiment. They were undergraduates and PhD students from the Philosophy Faculty and the History Faculty. 3 undergraduates and $11 \mathrm{PhD}$ students were involved in the poll.

Ukraine has the following regional composition: West, East, Centre, North, and South regions. The respondents presented all regions and the city of Kyiv, the capital of Ukraine, except the Autonomous Republic of Crimea and uncontrolled territories of Donetsk and Luhansk regions.

The survey and experiment were carried out at Taras Shevchenko National University of Kyiv. 
The statistical error of the survey does not exceed $0.3 \%{ }^{1}$.

\section{Instruments}

At the beginning of the experiment, the respondents were asked to listen to the musical tracks. For that to happen they were divided into 3 groups. The first group was invited to listen to Chopin's Nocturne in E-flat major, Op. 9, No. 2, the second - Prokofiev's Symphony No. 2 in D minor (Op. 40), and the third - White noise (sounds of nature). The running time of all tracks was about two minutes.

Then, soon thereafter, the participants were asked to watch the $A A A-A A A$ performance by Marina Abramovic \& Ulay ${ }^{2}$ within approximately 10 minutes. That video focuses on the relationship between two people, who are in the aggressive form of arguing, shouting at each other. Starting from a position of equality, they try to outdo each other.

After watching the performance, the respondents answered on the survey's question.

\section{Results}

An absolute majority of the respondents (71.5\%) reported they did not like the performance (in one degree or another). In contrast, only a quarter of the interviewees (28.5\%) enjoyed it. To the question what do you think is the video about the following answers were prevalent in the survey: (1) face-to-face arguing between very close people; (2) a splash of aggression and anger between arguers; (3) inability to control own emotions within an aggressive arguing.

While the respondents watching the performance, they wanted to get away from the scream of actors, to stop the torrent of hatred and aggression. Describing their feelings the respondents used such words as offensively, obnoxiously, anxiously, pain, anger, disquiet, annoyance, nervousness, etc. Nevertheless, some of the respondents asserted that the video generated their interest and it was surprising.

Almost all respondents agreed that aggression occurred in the performance. It was expressed in screaming, violation of personal space, an attempt to win the partner emotionally. In addition, the respondents drew attention to negative (aggressive) changes in voice tone, facial expressions and body movements. In general, the video was described by the following adjectives: aggressive, animal, annoying, wild, emotional, wrathful, strained, stressful, and grueling. However, there were such characteristics as interesting, genuine, edifying, profound, and $u$ seful.

Let us move on to the issue of how music tracks affected the respondent's experience of the performance. The analysis of the survey data has shown that $75 \%$ (3 members) of the respondents from group1, listened to Chopin's track, got more aggressive experience, concerning with the performance.

It should be noted that everyone listened to Chopin (5 people) known "Nocturne in E-flat major, Op. 9, No. 2" earlier and liked it. The participants indicated that the music track put them in a resting state, helped to relax and feel good. However, despite this recognition, the track was a reason strongly negative attitude to the video they just have seen. Thus, it is possible

\footnotetext{
${ }^{1}$ The statistical error was calculated by the formula that corresponds to the "standard deviation" rule, according to which the statistical error can be estimated at the $95 \%$ confidence interval, so the error will depend only on the sample size: $\mathrm{e}=1 / \sqrt{\mathrm{n}}$, where $\mathrm{e}$ is the statistical error, $\mathrm{n}$ is the sample size.

${ }^{2}$ See $A A A-A A A$ by Marina Abramović and Ulay, performance RTB, Liege, 1978: https://www.youtube.com/watch?v=KeaUOdvo0BA or https://vimeo.com/134398509
} 
to conclude that a positive attitude to the track, as well as the fact that the respondents were previously familiar with it, became that context increased the overall negative assessment of the performance. The state of calm and pleasure changed completely in the other direction during watching of the video. All these led to increased aggression and anxiety of the respondents and their negative evaluation of the performance in general.

The second group listened to Symphony No. 2 in D minor (Op. 40) by Prokofiev. Four out of five participants did not know this track. Only one person liked it, two members of this group had a neutral attitude, and yet two did not like it at all. On the one hand, two people asserted that the musical track influenced their ways to perceive the performance. On the other hand, three members of this group believed that music did not matter. At the same time, they described their feelings after listening like fear, anxiety, panic, displeasure, irritation, and anger. In this regard it can possible to conclude that Prokofiev's track had an influence on respondent's mental well-being while watching the performance. Their aggressiveness was increasing.

The third group listened to the sounds of nature (White noise) — neutral sounds from everyday life. All participants indicated that audio and video were emotionally separated; music had no impact on their mental well-being while watching the performance. Here in contrast to the previous groups, the film was viewed without a specific musical setting.

\section{Discussion}

Before the experiment, the respondents engaged in discussion concerning their arguing motivations, understandings, and reactions.

First up, they considered various ways of determining aggression in face-to-face arguing. The analysis of the respondent's views has showed that the absolute majority of interviewees were sure that aggressiveness primarily reflects the emotional state of the person.

Describing aggressive behavior in interpersonal communication, the students connected it with (1) negative emotional impact (threats, provocations) on arguers; (2) destabilization of opponent's mental state (psychological suppression); (2) numerous non-verbal factors concerning incredibly inappropriate body language of arguers (3) loss of self-control, provoked by outside factors, (4) verbal rejection of the opponent's point of view. Based on the definitions expressed during the discussion, we can conclude that Ukrainian youth links aggressiveness with an unusually powerful emotional influence on face-to-face arguing in general and arguers specifically. The respondents pointed out that rational approach to aggressiveness in interpersonal communication is almost impossible.

Further, the students discussed key factors affected on the level of aggression in face-to-face arguing and its manifestation in non-verbal argumentation. The interviewees identified that nonverbal manifestations of aggression are, on the one hand, overreacting, rude, and lewd gestures, and, on the other hand, a total absence of gestures. Also, it can be a raised voice tone; strong facial expressions, violation of personal space, contemptuous and deceptive behavior.

Additionally, the respondents discussed a number of outside factors. They do not link with face-to-face arguing directly but can affect the level of aggression of the participants. These factors could be divided into subjective and objective. The first group includes such traits as bad physical and mental health of arguers (physical exhaustion, psychological stress, personal problems leading to powerful negative emotion, etc.). The second group involves visual points (irritating visuals, too bright light, etc.) and audio factors (annoying sounds, too 
loud music, very strange noise, etc.). Also, the respondents incorporated to outside factors too close physical contact, previous negative experience of communication with the opponent, intervention of third parties, bad weather conditions (uncomfortable temperature, atmospheric pressure, etc.), volatile political situation, the use of obscene language, etc.

Summarizing, all respondents concluded that aggressiveness in face-to-face arguing cause hatred, anger and rejection of the opponent's view on the problem under discussion. They believed that aggressiveness in interpersonal communication is a hostile incursion into their personal world, leading to a conflict and serious dissents between arguers. Such aggressive activity tends to destroy their life and aggravate the interpersonal relations.

In case participation in face-to-face arguing the students asserted that, their behavior mostly is not aggressive. They do not offend people, incite hatred or anger, and provoke violence. The respondents identified themselves as peaceful and friendly. They try usually to maintain stability and avoid conflicts.

\section{Conlusions}

In this paper, we consider the key findings of an extensive empirical study concerning varied aspects of aggressiveness in face-to-face arguing. It has focused on the survey and experiment conducted in March 2019. The participants were undergraduates and $\mathrm{PhD}$ students studying philosophy, political science, and history at Taras Shevchenko National University of Kyiv.

Focusing on young people aged 18 to 25 , which present all regions of Ukraine except the Autonomous Republic of Crimea and uncontrolled territories of Donetsk and Luhansk regions the survey provides a mini-snapshot of Ukrainian youth, born between the mid- 90s and mid2000s.

The first research question of our project was the following, what are Ukrainian youth attitudes towards aggressiveness within interpersonal communication? The analysis of received data has shown that Ukrainian youth has a strongly negative attitude to disputes in which aggressive emotions predominate. Aggression is considered as something unacceptable for the human person. According to the research, aggressive behavior in face-to-face arguing often causes emotional pain, deep stress and other negative impacts on the mental health of arguers. All of these points lead to quarrel instead of conflict resolution. Therefore, Ukrainian youth identify aggressiveness as a reason for improving disagreement in face-to-face arguing.

According to the majority of responses, Ukrainian students are predominantly tolerant, peaceful, and friendly. They prefer to express respect and sympathy for others and to argue constructively or do not enter the arguing at all.

As can be seen, there are large areas of overlap between the data of two surveys, conducted in 2018 and 2019.

Further, we were interested in the issue: what are the reasons for increasing the level of aggressiveness in face-to-face arguing? In order to identify some of them, we conducted the experiment with such argumentative tools as different music tracks and the video performance $A A A-A A A$ by Marina Abramovic \& Ulay. While this experiment the last was seen as a model of face-to-face arguing. This research made it possible to identify the direct and indirect musical impact on the aggressiveness levels.

In the first case, listening to aggressive music (Prokofiev's Symphony No. 2 in D minor. $O p .40$ ) contributed to the strengthening of aggressiveness while watching video performance AAA-AAA by Marina Abramovic \& Ulay. This result was expected for us. 
The second group of the respondents listened to calm and pleasant music (Chopin's Nocturne in E-flat major, Op. 9, No. 2). There we have received the results impressed us. Calm and relaxed music led to the increasing of aggressiveness within watching the performance. The respondents highlighted that it was the effect of dramatic contrast.

Above we present the main results of our research, discoveries and generalizations that have attracted our attention. However, we understand that it is only the tip of the iceberg and further detailed analysis of Ukrainian youth attitudes towards aggressiveness in interpersonal arguing should occur in future.

\section{References}

Eemeren, Frans Hendrik van. Argumentation theory and argumentative practices: A Vital but Complex Relationship. Informal Logic, 37 (4), 2017: 322-350.

Eemeren, Frans Hendrik van. Bingo! Promising developments in argumentation theory. Reflections on theoretical issues in argumentation theory. Heidelberg etc.: Springer, 2015: 3-25.

Finocchiaro, Maurice A. Arguments about arguments. Systematic, critical and historical essays in logical theory. Cambridge: Cambridge University Press, 2005.

Finocchiaro, Maurice A. Two empirical approaches to the study of reasoning. Informal Logic, 1994, 16: 1-21.

Finocchiaro, Maurice A. Defending Copernicus and Galileo. Critical reasoning in the two affairs. Dordrecht: Springer, 2010.

Finocchiaro, Maurice A. Galileo and the art of reasoning: rhetorical foundations of logic and scientific method. Boston, MA: Reidel, 1980.

Finocchiaro, Maurice A. Meta-argumentation. An approach to logic an argumentation theory. London: College Publications, 2013.

Hample, Dale. Interpersonal arguing, New York: Peter Lang, 2018.

Hample, Dale Arguing skill. Handbook of communication and social interaction skills. Mahwah, NJ: Lawrence Erlbaum, 2003: 439-478.

Hample, Dale. Arguing: exchanging reasons face-to-face. Mahwah, NJ: Lawrence Erlbaum, 2005.

Hample, Dale, and Anagondahalli, Deepa. Understandings of arguing in India and the United States: Argument frames, personalization of conflict, argumentativeness, and verbal aggressiveness. Journal of InterculturalCommunication Research. 44 (1), 2015: 1-26.

Hample, Dale, and Cionea, I. A. Taking conflict personally and its connections with aggressiveness. Arguments, aggression, and conflict: New directions in theory and research. New York, NY: Routledge, Taylor, and Francis, 2010: 372-387.

Hample, Dale, \& Dallinger, Judith M. A Lewinian perspective on taking conflict personally: Revision, refinement, and validation of the instrument. Communication Quarterly, 43 (3), 1995: 297-319.

Hample, D., Han, Bing, and Payne, David. The aggressiveness of playful arguments. Argumentation, 2010, 24 (4): 405-421.

Hample, Dale, and Irions, Amanda L. Arguing to display identity. Argumentation, 29 (4), 2015: 389-416.

Hample Dale, and Rapanta, Chrysi. Orientations to interpersonal arguing in the United Arab Emirates, with comparisons to the United States, China, and India. Journal of Intercultural Communication Research, 44 (4), 2015: 263-287. 
Infante, Dominic. A., and Rancer, Andrew S. A conceptualization and measure of argumentativeness. Journal of Personality Assessment, 46, 1982:72-80.

Infante, Dominic A., and Charles J. Wigley III. Verbal aggressiveness: an interpersonal model and measure. Communication Monographs, 53, 2009: 61-69. https://doi. org/10.1080/03637758609376126

Khomenko, Iryna. Empiricalization as a Trend in Argumentation Study. Future Human Image. 10, 2018: 20-28. https://doi.org/10.29202/fhi/10/2

Lewiński Marcin, Hample Dale, Sàágua João, \& Mohammed Dima Arguing in Portugal: A cross-cultural analysis. Journal of International and Intercultural Communication, 2018: 233-253. 